\title{
Exercise Testing Protocols to Detect the Presence of Coronary Artery Disease: Bruce or Ramp?
}

Ricardo Vivacqua Cardoso Costa ${ }^{(1)}$

Hospital Pró-Cardíaco, Rio de Janeiro, RJ - Brazil

Editorial referring to the article: Comparison between Bruce and Ramp Protocols for Exercise Testing in the Diagnosis of Myocardial Ischemia.

The investigation of ischemic response through clinical, metabolic, hemodynamic, and electrocardiographic parameters displayed in the exercise stress test (ET) in multifactorial analysis increases the ET's diagnostic and prognostic accuracy indication of ischemic response. ${ }^{1}$

Coronary artery disease (CAD) is a pathology that requires quick and safe decisions for the patient, and it is always a challenge. The protocols for performing the ET, whether on a cycle ergometer or a treadmill, must be adapted to the patient's biomechanical conditions so that they are comfortable and can reach the criteria that define a maximum or close to the maximum effort level. The protocol must seek a satisfactory mobilization of myocardial reserves so that the sensitivity to the presence of an ischemic response can be increased. ${ }^{2}$

Myers et al. ${ }^{3}$ compared ramp protocols versus standardized protocols. They inferred that protocols with progressive increments of loads and an average duration of ten minutes, such as the ramp tests, establish a better relationship between oxygen consumption and the applied load and minor variation in the "slope" between the two variables in a regressive way, considering that this test appears to be better when applying equations to estimate oxygen consumption. They conclude that the individualized ramp protocol on a treadmill exhibits the best linear relationship between oxygen consumption and applied load, preferable when there is no equipment for direct gas measurement.

\section{Keywords}

Exercise; Testings; Protocols; Detect; Presence.
Noël et al. ${ }^{4}$ compared exercise-induced myocardial ischemia in coronary patients submitted to exercise tests performed with the Bruce protocol, treadmill ramp, and cycle ergometer ramp. They evaluated the onset of ST depression $(-1.0 \mathrm{~mm}$ or more), characterizing the ischemic threshold (IT), relating it to the double product, equivalent to myocardial oxygen consumption and maximum oxygen consumption $\left(\mathrm{V}^{\prime} \mathrm{O}_{2}\right)$. The IL was higher during the cycle ergometer ramp protocol (DP:24009 \pm 5769 ) when compared to the Bruce protocol (DP:20429 \pm 3508 ) and treadmill ramp (DP:19451 \pm 3392 ), regardless of $\mathrm{V}^{\prime} \mathrm{O}_{2}$, which did not exhibit significant differences between the tests. Thus, they concluded that the type of exercise applied in a test, which is more important than the type of protocol, is associated with a variation in electrocardiographic parameter indications of myocardial ischemia, regardless of the intensity of effort and myocardial oxygen demand.

Many studies contributed to legitimizing exerciseinduced myocardial ischemia. We highlight the "ischemic cascade" in which metabolic and biochemical changes are observed at the beginning of myocardial ischemia, soon after perfusion reduction, which is then followed by the contractile changes electrocardiogram and, finally, precordial pain. ${ }^{5}$ Various methods can identify these. We believe that the Cardiopulmonary Exercise Test, using hemodynamic variables, such as the oxygen pulse curve, related to systolic volume, often at a plateau or descending with the progression of exercise, ${ }^{6}$ can better display left ventricular dysfunction at the onset of ischemia.

In the study, "Comparison between the Bruce and Ramp protocols in the Treadmill Test for the Diagnosis of Myocardial Ischemia,"7 the authors conclude

Mailing Address: Ricardo Vivacqua Cardoso Costa

Av. Afrânio de Melo Franco, 365, apt. 101. Postal Code: 22430-060, Rio de Janeiro, RJ - Brazil.

E-mail: vivacqua@cardiol.br, rvivcosta@gmail.com 
that the Bruce protocol had a greater sensitivity for detecting ischemia in the exercise test, while the ramp protocol had better specificity and accuracy. Despite highlighting the greater sensitivity of the Bruce Protocol for the diagnosis of exertion-induced myocardial ischemia, they mention the advantage of the ramp protocol in better adapting to the biomechanical conditions of patients with protocols that use steeply staggered load increments. The results obtained in myocardial perfusion scintigraphy with physical stress were used as a reference standard, without reference to the applied protocol. Although the authors evaluated changes in the ST segment during exercise and recovery, there was no relationship with the electrocardiographic lead where the change in ventricular repolarization occurred. The authors comment that the interpretation of the exercise test should not be limited only to the electrocardiographic pattern. They considered the clinical and hemodynamic variables of fundamental importance in interpreting the results, allowing for diagnostic and prognostic inference. A well-designed study with a larger sample size will contribute to other research in this crucial area of Exercise Medicine.

When performing an exercise test, we can conclude that poor adaptation to exercise or excessive loads can generate undefined changes, compromising the test result. Therefore, the test, either performed on a treadmill or a cycle ergometer, must always be adapted to the clinical and biomechanical conditions of the patients for an accurate interpretation of clinical, metabolic, hemodynamic, and electrocardiographic variables.

\section{References}

1. Carreira MAMQ. Metodologia do Teste Ergométrico. In: Costa RVC, Carreira MAMQ. Ergometria: Ergoespirometria, Cintilografia e Ecocardiografia de Esforço. Rio de Janeiro: Editora Atheneu; 2009.

2. Serra S. Reabilitação Cardiopulmonar e Metabólica na Coronariopatia. In: Araujo W. O Exercício físico na saúde e nas doenças cardiovasculares.2021, no prelo.

3. Myers J, Buchanan N, Walsh D, Kraemer M, McAuley P, Hamilton-Wessler $\mathrm{M}$, et al. Comparison of the Ramp Versus Standard Exercise Protocols. J Am Coll Cardiol. 1991;17(6):1334-42. doi: 10.1016/s0735-1097(10)80144-5 .

4. Noël M, Jobin J, Marcoux A, Poirier P, Dagenais G, Bogaty P. Comparison of Myocardial Ischemia on the Ergocycle Versus the Treadmill in Patients with Coronary Heart Disease. Am J Cardiol. 2010;105(5):633-9. doi: 10.1016/j. amjcard.2009.10.057.

5. Mastrocolla LE. Manifestações Eletrocardiográficas e não eletrocardiográficas no Teste Ergométrico, Cardiopatia Isquêmica. In: Serra S, Leão R, editors. Teste Ergométrico, Teste Cardiopulmonar de Exercício, Cardiologia Nuclear, Reabilitação Cardiopulmonar e Metabólica e Cardiologia do Esporte e do Exercício. Rio de Janeiro: Elsevier; 2020 .

6. Belardinelli R, Lacalaprice F, Carle F, Minnucci A, Cianci G, Perna G, et al. Exercise-induced Myocardial Ischaemia Detected by Cardiopulmonary Exercise Testing. Eur Heart J. 2003;24(14):1304-13. doi: 10.1016/s0195$668 \times(03) 00210-0$.

7. Fagundes TTS, Mizzaci CC, Buglia S, Wohnrat FC et al. Comparison between Bruce and Ramp Protocols for Exercise Testing in the Diagnosis of Myocardial Ischemia.Int J Cardiovasc Sci. 2022; 35(1): 28-36. 